\title{
Sorbitol-Induced Diabetic-Like Retinal Lesions in Rats: Microscopic Study
}

\author{
Gaber A. Ramadan \\ Biology Department, UAE University, Al-Ain, UAE
}

\begin{abstract}
The present study investigated the sorbitol toxicity on the retinas of normal albino rats and founded by the light microscope that intra-peritoneal injection of Sorbitol $(10-\mathrm{mg} / \mathrm{kg}$-body weight per day) for 24 weeks produced similar diabetic like retinal lesions in these rats. The retinopathic effects of sorbitol injection affect retinal microvessels, pigment epithelium, neural retina and glial cells. Cytoplasmic vacuolation of the pigment epithelium and oedema of the neural retinal cells were evident. Microvascular abnormalities include thick-walled, elongated and dilated blood capillaries. The abnormal capillaries showed aneurysms and were occluded with deformed, fragmented, and adherent blood cells. Another finding was the pyknosis of glial cells. The present investigation concluded that sorbitol is toxic to the retinal tissue and it may play a role in the setup of diabetic retinopathy.
\end{abstract}

Key words: Diabetes, Diabetic retinopathy, Sorbitol, Rats

\section{INTRODUCTION}

Diabetes mellitus is a major medical problem throughout the world. It causes an array of long-term systemic complications ${ }^{[1]}$. Among these complications is the diabetic retinopathy, which characterized by the increase in capillary permeability ${ }^{[2]}$, thickening of the basement membrane ${ }^{[3,4]}$, pericyte necrosis followed by the capillary occlusion, microaneurysms, endothelial cell proliferation, haemorrhage, oedema, neovascularization $^{[5,6]}$ and lately, a fibrous or glial tissue often grows with the vessels to a degree that traction and distortion of the retina may occur, producing retinal damage and retinal detachment ${ }^{[7]}$ and resulting in blindness ${ }^{[8]}$.

Several authors suggested the pathophysiology of diabetic retinopathy. It is mainly related to the sorbitol pathway ${ }^{[9]}$ and also the non enzymatic glycation of proteins ${ }^{[10]}$. The longest running controversy among researchers and clinicians studying diabetic retinopathy is the role of sorbitol pathway, particularly its initial enzymatic step, and the reduction of glucose to sorbitol in the presence of aldose reductase. On the contrary, some authors could not demonstrate aldose reductase enzyme in normal rat retinal vessels by immunechemical methods ${ }^{[11]}$. Also, sorbitol and fructose are mildly elevated in cultured rhesus monkey pericyte cells in a medium containing high concentration of glucose ${ }^{[12]}$. Engerman and Kern ${ }^{[13]}$ in their studies found that the aldose reductase inhibitor sorbinil did not prevent the development of diabetic retinopathy. Dissimilarly, ${ }^{[14,15]}$ showed that diabetic like lesions in rats fed a galactose diet prevented with (tolrestat) an aldose reductase inhibitor. In addition, several reports were ascribed the diabetic retinopathy to the direct effect of high concentration of glucose on the cell multiplication and protein synthesis ${ }^{[16]}$. Hammes et al. ${ }^{[17]}$ reported that inhibition of glycoprotein formation or retardation of diabetic retinopathy achieved by using of glycoprotein formation inhibitor aminoguanidine. According to these controversial evidences, the aldose reductase pathway may not be accused in the production of diabetic retinopathy or it may affect the retinal tissue indirectly and in association with other tissues harmful factors.

\section{MATERIALS AND METHODS}

Animals and Experiments: Thirty-five male albino rats weighing 150-200 g were used. Animals were fed with standard laboratory chow and allowed drinking water ad libitum. The animals were divided into two groups: the first group of 15 rats served as control. The second group of 20 rats was used for studying the effect of intraperitoneal sorbitol-injection on the albino rats retinas.

Dosage: Control rats were injected daily with a single dose of $150 \mathrm{mM}$ sodium chloride into the peritoneal cavity for six months. Also rats of group two were injected daily with $10-\mathrm{mg} / \mathrm{kg}$-body weight sorbitol (Sigma Chemical Company, St. Louis, MO, USA) dissolved in $150 \mathrm{mM} \mathrm{Na} \mathrm{Cl}$ solution into the peritoneal cavity for six months.

Light Microscope Preparation: Eyes were excised from the rats under light ether anesthesia after 4, 8, 12, 16,20 and 24 weeks of administration experiments. The eyes were immediately fixed in $4 \%$ glutaraldehyde buffered at $\mathrm{pH}$ 7.3. Retinal tissue was then removed and further fixed in phosphate buffered $1.3 \%$ osmium tetroxide ( $\mathrm{pH}$ 7.3) for 2 hours. The sample were then processed and embedded in araldite Cy212 according to the procedure of Glauret ${ }^{[18]}$. Semithin sections were cut with an LKB ultratome, (LKB, Bromma, Sweden) and stained with touludine blue and examined by the light microscope. Retinal tissue from control animals was processed and examined simultaneously for comparison. 

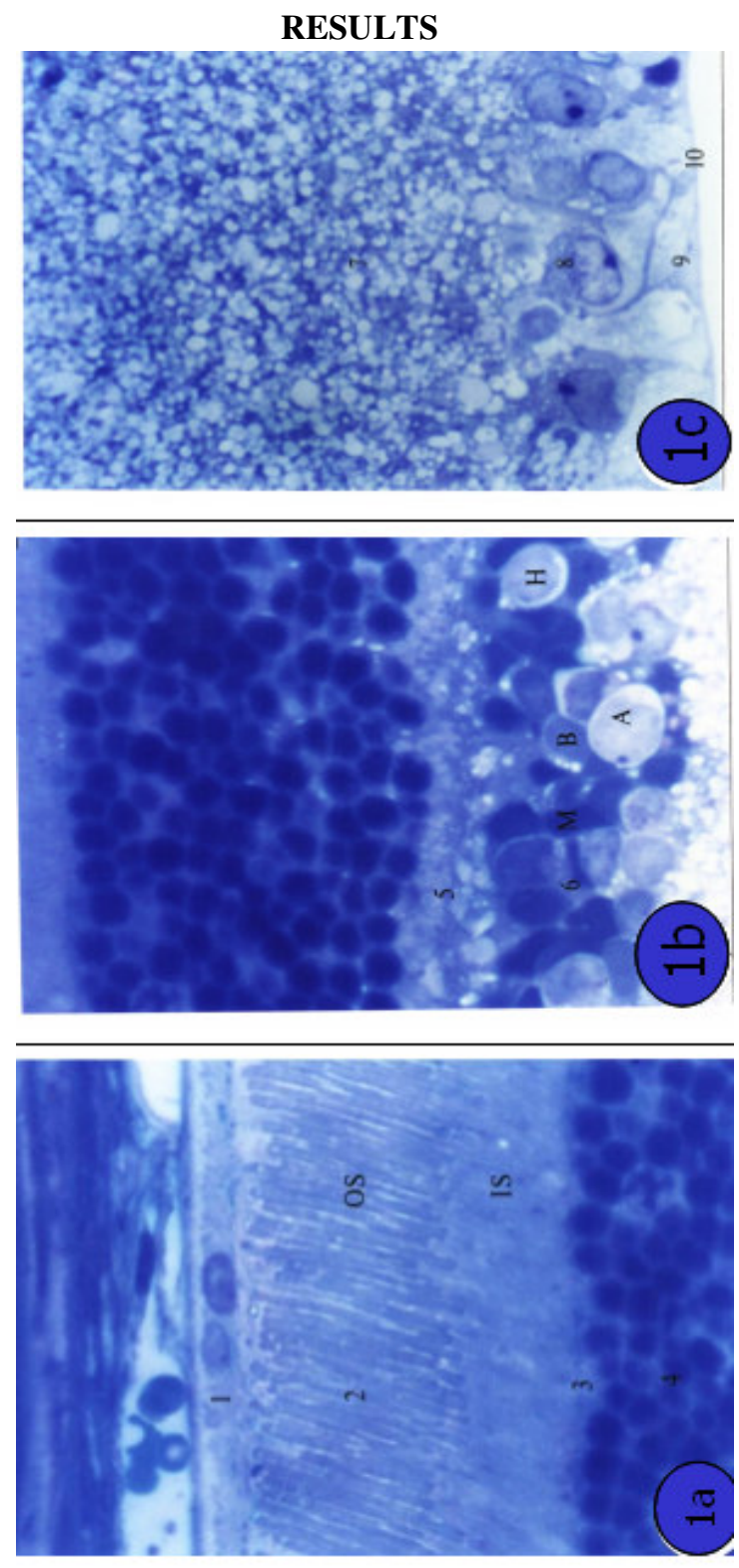

Fig.1a. L.M. (Toluidine blue, X 1,250) of semi-thin section of control albino rat showing: (1) pigment epithelium, (2) photoreceptor layer, OS = outer segments, IS = inner segments, (3) outer limiting membrane, (4) part of the outer nuclear layer.

Fig.1b. L.M. (Toluidine blue, X 1,250) of semi-thin section of control albino rat showing: (5) outer plexiform layer, (6) inner nuclear layer. Notice the horizontal cell $(\mathrm{H})$, bipolar cell (B), amacrine cell (A), and Müller cell (M).

Fig.1c. L.M. (Toluidine blue, X 1,250) of semi-thin section of control albino rat showing: (7) inner plexiform layer, (8) ganglion cell layer, (9) nerve fiber layer, (10) inner limiting membrane.

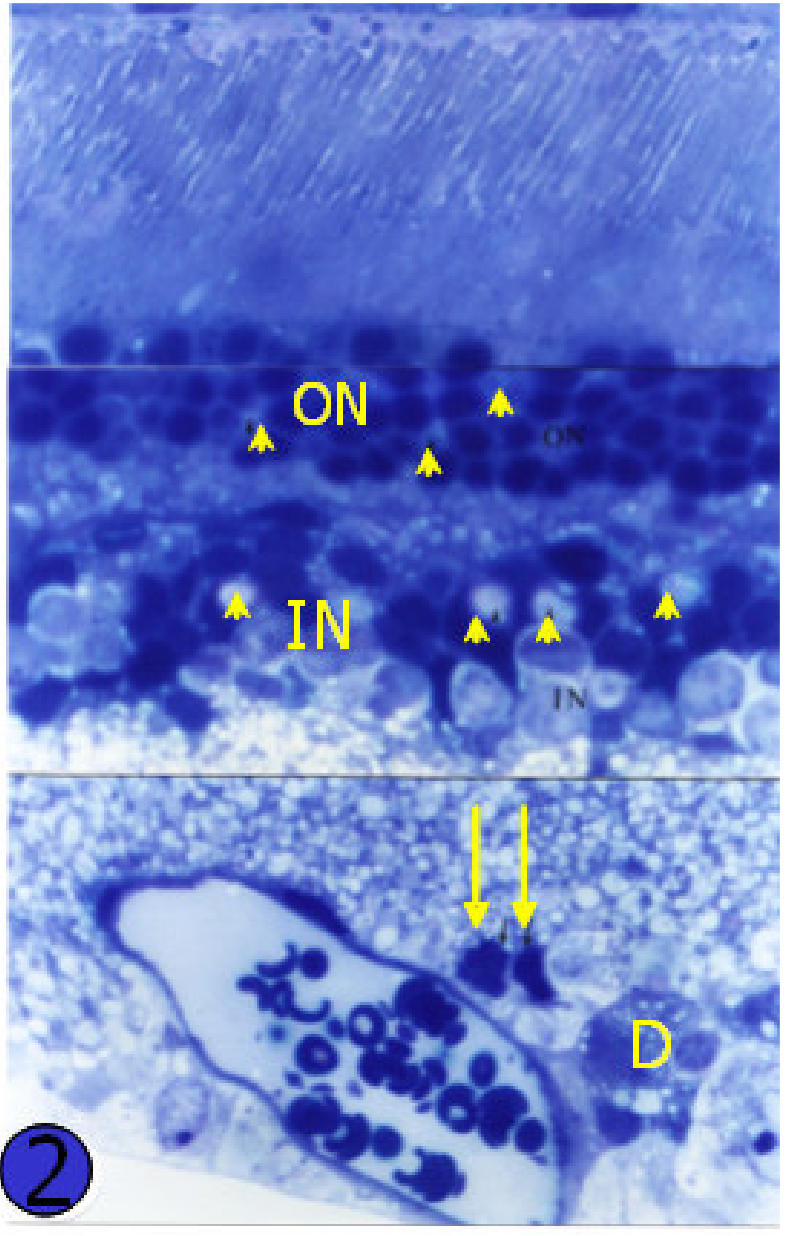

Fig.2. Light micrograph of semi-thin section of a rat retina injected with sorbitol for 4 weeks showing vacuoles of pigment epithelium (V) and lucent areas (arrowheads) in the outer nuclear $(\mathrm{ON})$ and inner nuclear (IN) layers. A giant retinal capillary is occupying the ganglion cell and inner plexiform layers. Pyknosis of glial cells (arrows) near to the dilated capillary is evident. Notice the dark stained area (D) near to the capillary wall. Toluidine blue. X 1250

Histological changes of the retina of sorbitol injected group after 4 weeks: The most prominent changes observed in the retina of animals treated with sorbitol for 4 weeks were the cytoplasmic vacuoles of the pigment epithelial cells and lucent areas in the inner and outer nuclear layers. In addition, giant retinal capillaries with thick basement membrane were occupying the ganglion cell and inner plexiform layers. The lumens of these dilated capillaries were filled with fragmented, deformed, and adherent red blood cells (Fig. 2) 


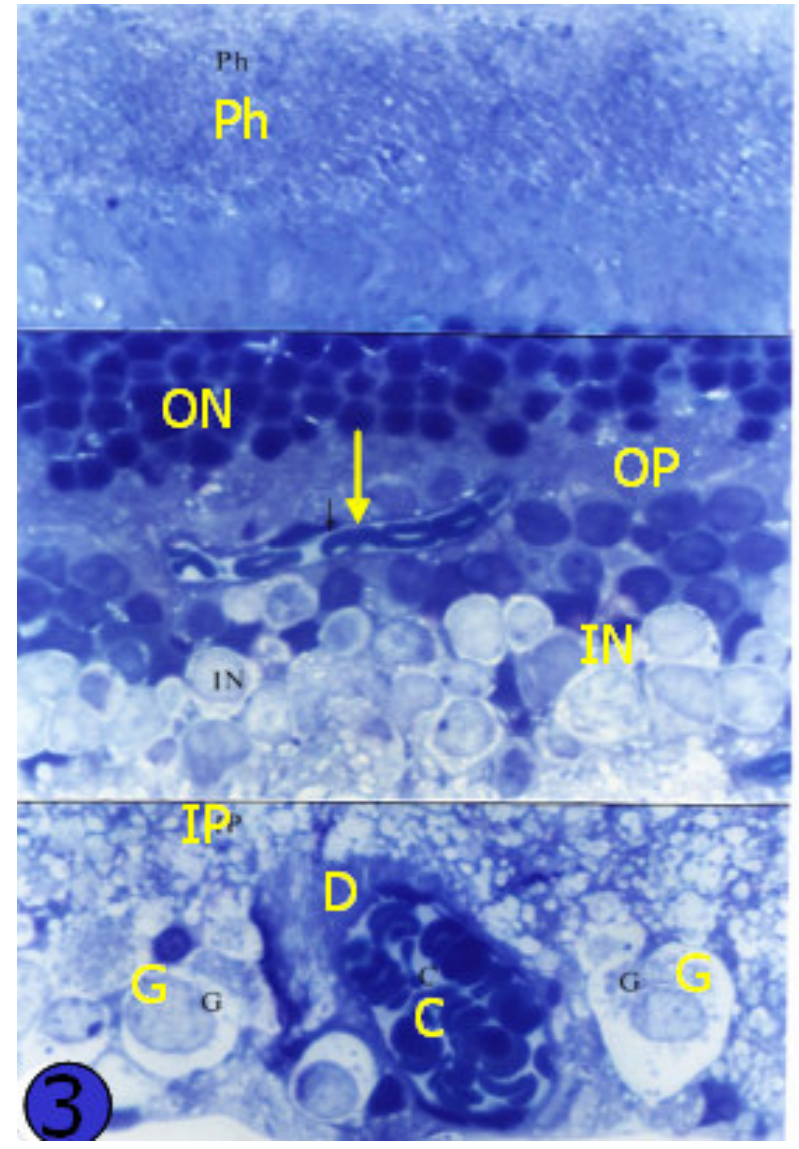

Fig.3. Light micrograph of semi-thin section of a rat retina injected with sorbitol for 8 weeks showing accumulation of dark stained bodies in the pigment epithelium. Fragmentation of the photoreceptor layer $(\mathrm{Ph})$ was evident. A dilated retinal capillary (C) is seen in the ganglion cell layer. Dark stained tissue (D) is seen near to this abnormal capillary. Another elongated capillary appeared in the outer plexiform layer (arrow). The cytoplasm of the ganglion cells appears lucent. Oedema is evident in the inner nuclear (IN), inner plexiform (IP) and ganglion cell (G) layers. Toluidine blue. X 1250

Histological changes of the retina of sorbitol injected group after 8 weeks After 8 weeks of sorbitol injection, the retinas of the rats showed fragmentation of photoreceptor layers. Vacuoles appeared inbetween the outer nuclear layer. Oedema of the inner nuclear, inner plexiform and ganglion cell layers is evident. The cytoplasm of the ganglion cells appeared lucent. A dilated thickened retinal capillary is seen in the ganglion cell layer. The lumen of the capillary is obliterated by several adherent red blood cells. A dark stained tissue area was noticeable near to this capillary. Another elongated boat-shaped blood capillary extended from the outer plexiform layer to the inner nuclear layer (Fig. 3)

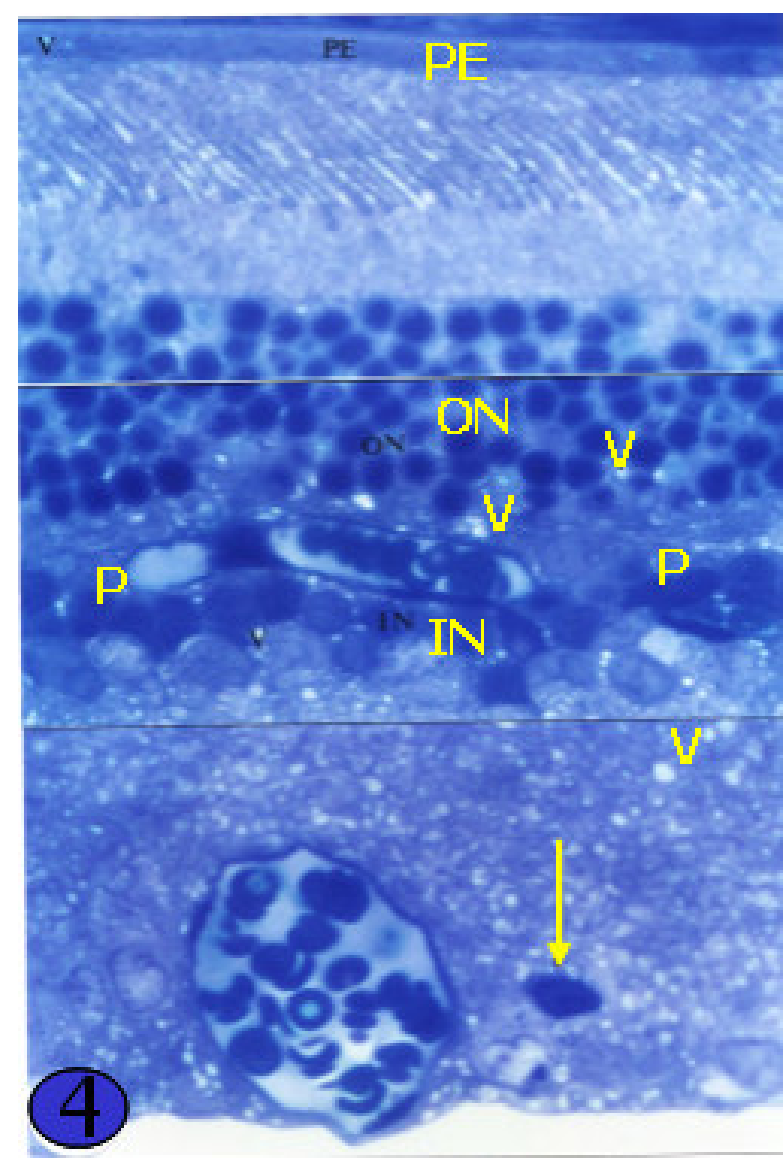

Fig.4. Light micrograph of semi-thin section of a rat retina injected with sorbitol for 12 weeks showing vacuolation (V) of the pigment epithelium (PE), outer nuclear $(\mathrm{ON})$ and inner nuclear (IN) layers. Most of the outer nuclear layers showed pyknosis (P). An elongated, occluded capillary is seen in the outer plexiform layer. Another giant capillary with thick basement membrane occupied the nerve fiber, ganglion, and inner plexiform layers. Notice the pyknotic glial cell (arrow) near to the ganglion cell. Toluidine blue. X 1250

Histological changes of the retina of sorbitol injected group after 12 weeks: Examinations revealed vacuoles of the pigment epithelium, outer nuclear and inner nuclear layers. A dilated capillary with thick wall occupied part of the nerve fibre, ganglion cell, inner plexiform layers. A nother extended blood capillary with occluded lumen is evident in the outer plexiform layer. Pyknosis of glial cells was also evident in this duration. (Fig. 4)

Histological changes of the retina of sorbitol injected group after 16 weeks: The retinas of sorbitol treated rats for 16 weeks showed disintegration of photoreceptor layer and oedema of the outer nuclear, 


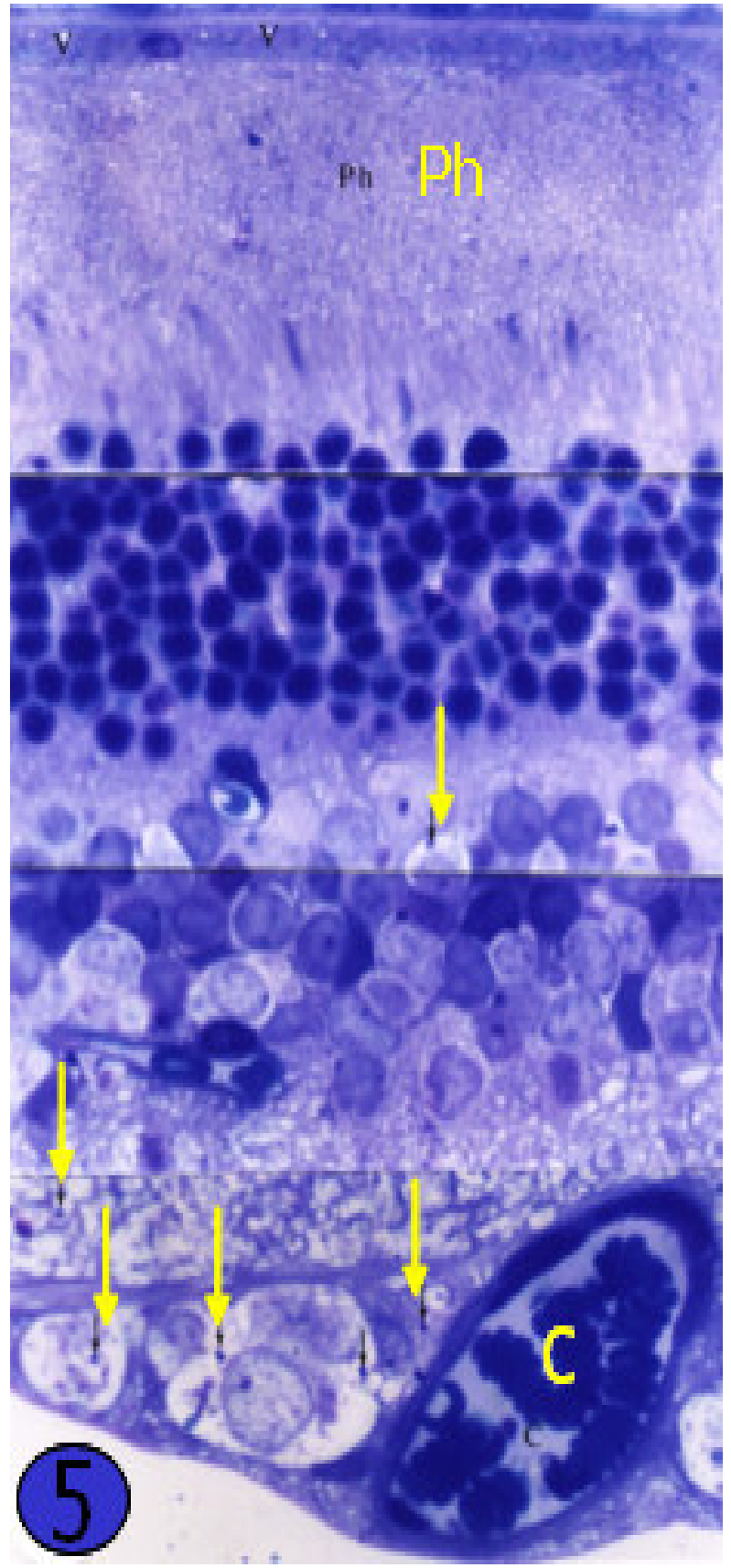

Fig.5. Light micrograph of semi-thin section of a rat retina injected with sorbitol for 16 weeks showing vacuoles (V) in the cytoplasm of the pigment epithelium layer. Notice the presence of dark stained bodies in the retinal pigment epithelium Disintegration of the photoreceptor layer $(\mathrm{Ph})$ is evident. Notice the dilated thick-walled retinal capillary $(\mathrm{C})$ in the ganglion cell layer. The lumen of this blood capillary was narrowed by deformed adherent of red blood cells which indicate thrombosis. In addition, dark stained bodies are accumulated (arrows) in the inner nuclear, inner plexiform and ganglion cell layers. Toluidine blue. X 1250

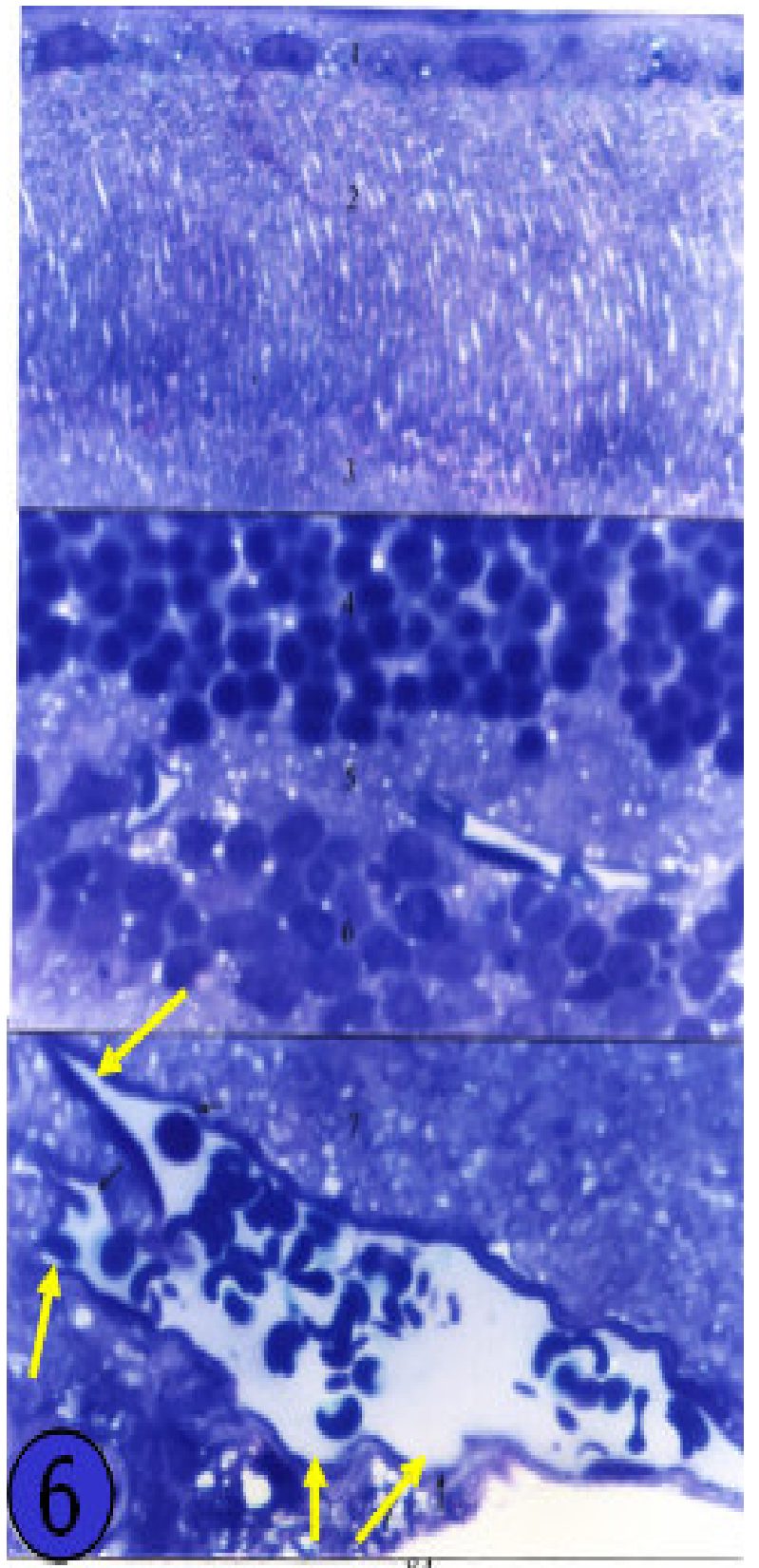

Fig.6. Light micrograph of a semi-thin section of a rat retina injected with sorbitol for 20 weeks showing vaculation and accumulation of dark stained bodies in the retinal pigment epithelium (PE). Clear spaces are seen among the outer segments and inner segments of photoreceptors. Most of the retinal layers appeared thickened due to oedema. Thick walled dilated retinal capillary with proliferated endothelial cells and microaneurysms points are obvious (arrows). Notice the fragmented, deformed and adherent red blood cells that fill the lumen of the capillary. Toluidine blue. X 1250 
outer plexiform, inner nuclear, inner plexiform and ganglion cell layer. A thick walled retinal capillary appeared in the ganglion cell layers. The lumen of this blood capillary was narrowed by deformed agglutinations of red blood cells which indicate thrombosis. These red blood agglutinations were attached to the wall of the capillary. The disruption of the inner limiting membrane was another finding in this duration (Fig. 5)

Histological changes of the retina of sorbitol injected group after 20 weeks: Semi-thin sections of the retinas of rats treated for 20 weeks revealed that both pigment epithelium and neural retina were affected by sorbitol. The pigment epithelium showed vacuolation in the cytoplasm. Clear spaces were seen between the outer and inner segments of photoreceptors. Oedema of the outer and inner plexiform layers, outer nuclear, inner nuclear, the ganglion cell, and nerve fiber layers was noticeable. Thick-walled and dilated retinal capillary was also evident. Outpushing from the wall of the dilated retinal capillary in several parts was apparent. Karyolysis of some ganglion cells was noted (Fig. 6)

Histological changes of the retina of sorbitol injected group after 24 weeks: After 24 weeks of sorbitol treatment, the retinal pigment epithelium appeared completely vacuolated. The connections between the outer and inner segments of photoreceptors were ruptured in many areas. Oedema of the photoreceptors, outer and inner plexiform, outer and inner nuclear layer, and ganglion cell layer was evident. The finding of dilated, elongated, and occluded retinal capillaries was characteristic in this duration. In addition, the ganglion cell layer showed dissolution of their nuclei (Fig. 7)

\section{DISCUSSION}

In the present study, it was remarkable to find similar diabetic like retinal-lesions in the sorbitol injected rats. Sorbitol injection caused early microangiopathy in the retinal capillaries. The blood vessels appeared dilated, occluded, with thickened basement membranes and evident aneurysms. Edema followed the microangiopathy. The cytoplasm of some neural cells was lucent and containing dark stained bodies. Dissolution of ganglion cell nucleus was evident. Another morphologic change, which appeared earlier due to sorbitol injection, was the pyknosis of Müller cells. The pigment epithelial cells showed vacuolation and the photoreceptors were damaged in a similar manner as documented in diabetic rat retinas.

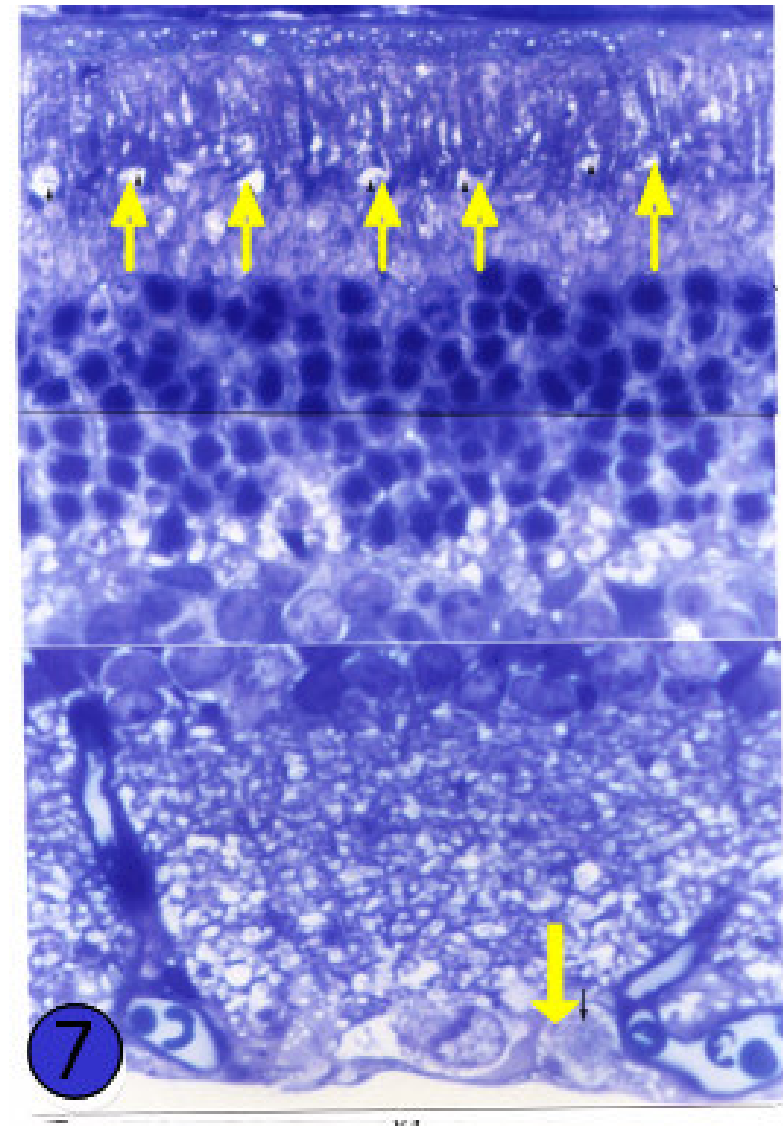

Fig.7. Light micrograph of semi-thin section of rat retina injected with sorbitol for 24 weeks showing severe vacuolation and accumulation of dark stained bodies in the retinal pigment epithelium of retinal pigment epithelium. Oedema of the photoreceptors, outer and inner plexiform, outer and inner nuclear layer, and ganglion cell layer is clear. Large elongated retinal capillaries are extending from the ganglion cell layer to the inner nuclear layer. Notice the occluded lumens of these blood capillaries. In addition, dissoluted nucleus (arrow) of ganglion cell is evident. The connections of the outer and inner segments of photoreceptors were lost in many areas (arrow heads). Toluidine blue. X 1250

Similarly, as in diabetic retinopathy, in the present work, sorbitol induced diabetic rats showed early retinal microvascular changes. By the light microscope, the microvessels appeared dilated and occluded with aggregates of deformed and adherent blood cells. In addition, most of these blood capillaries showed aneurysm formation. Also, leakage of dark stained homogenous material near to the aneurysms was evident.

The variety of hematological abnormalities seen in diabetes, such as erythrocyte deformatibility, aggregation or adhesion and raised blood platelet level 
are findings in patient with diabetes mellitus, predisposed to sluggish circulation, endothelial damage and focal capillary occlusion. These contribute to the development of diabetic retinopathy ${ }^{[1,19-21]}$.

In addition, small areas of capillary closure result in dilated capillaries and increased intracapillary pressure will lead to leakage through the vessel wall ${ }^{[19]}$. Also, the ruptured microaneurysms result in retinal hemorrhage. Increased permeability at the sits of vascular outpouching and ruptured of the blood capillaries results in leakage of fluid and proteinaceous material $^{[22]}$, which appeared in the present work as dark exudates near to the aneurysm points.

One of the main features of diabetic retinopathy is oedema in the retinal tissue ${ }^{[23-26]}$. Similarly, in the present work, retinas from sorbitol induced diabetic rats showed retinal oedema that appeared in several layers of the retina; the photoreceptors, the plexiform layers, the inner nuclear layer, and the ganglion cell layer. It may be suggested that the observed oedema in the inner segments may be due to the ruptured connections with the outer segments and diminished removal of the latter. Due to edema, a hydrostatic pressure may be created leading to the swelling of the photoreceptor inner segments and disrupting the connections between the outer an inner segments of photoreceptors. This effect of oedema is more clear after microangiopathy which appeared earlier in the present work.

It is well known that cells of lining epithelia concerned primarily with absorption, secretion, excretion, and transport commonly show folding of the plasma membrane at the apical and basal cell boundaries. The retinal pigment epithelium is a representative tissue of this class, acts as a barrier between permeable blood vessels of the choriocapillaries and the neural retina. Extracellular passage of water soluble substances between retina and choroid is hindered by the tight junctions that connect the lateral surfaces of the cells near their apical border; instead choroidal-retinal exchange is transcellular. Fine villi processes at the apex of the cell and complex infolding of the plasma membrane at the base increase the surface area at these boundaries many times over that of planner borders ${ }^{[27]}$.

In addition, the retinal pigment epithelial cells secretes a hyaluronan-rich extracellular matrix called the interphotoreceptor matrix, fills the narrow spaces between the retinal pigment epithelium and photoreceptors. Since the photoreceptors lack a direct blood supply, the retinal pigment epithelium is responsible for regulation of material passage between the choroid and the photoreceptors. The retinal pigment epithelium contains the enzyme needed for the visual cycle process. Also, the retinal pigment epithelial cells cleared the shedding of photoreceptors debris by phogocytosis of shedding outer segments ${ }^{[28]}$.

In general, most of the functions of the pigment epithelium may be disturbed due to the early morphological changes seen in the present and other similar investigations ${ }^{[29]}$. The pigment epithelium, showed vacuolation, and the accumulation of dark stained bodies suggested to be lysosomes or cellular debrises. Aizu et al. ${ }^{[2]}$ found that the pigment epithelium is affected by streptozotocin induced diabetes and showed vacuolation, damaged mitochondria, and accumulation of lysosomes and suggested that thease alterations may deplete the trophic factors by the pigment epithelium.

In the present study, the accumulation of such large amounts of dark stained bodies within the cytoplasm of the pigment epithelium of sorbitol injected rats indicates that they are not functioning efficiently in the lytic process. This suggestion is confirmed by the presence of unusual damaged photoreceptors, gaps or spaces between outer and inner segments of the photoreceptors. These gaps indicate the inability of the microvilli to surround and engulf the outer and inner tips of the photoreceptors as a result of the changes that were seen in the pigment epithelium cells.

On the other hand, the different structural changes of the pigment epithelial cells in the present work led to functional impairment of the pigment epithelium. This assumption may be in agreement with the suggestion of Eva $^{[19]}$ who postulated that the damaged cells of the pigment epithelium due to diabetic retinopathy could not reabsorb the leakage materials from weakened vessels. Thus, increased leakage and reduced removal of fluids inducing oedema and visual loss.

In the present investigation, one of the main effects of sorbitol retinopathy was directed towards the photoreceptors. Light microscopic studies of 8 weeks after sorbitol injection revealed the photoreceptors were fragmented. In addition, disintegration and rupture of connection between the outer and inner segments of the photoreceptors were found after 16 and 20 weeks respectively. The inner and outer segments of photorecetors appeared oedematous.

The changes in the photoreceptor layer in the present investigation are in general agreement with the work of Aizu et al. ${ }^{[29]}$ who found that the damage of the photoreceptors in induced streptozotocin diabetic rats and with the work of Grahn and Cullen ${ }^{[30]}$ who found degeneration of photoreceptors outer and inner segments were swollen and pale stained. Also, the pigment epithelium in diabetic dogs was vacuolated and hypertrophied after 5-months. 
Many of the diabetic literatures stressed up on the microvascular changes in diabetes mellitus. However, only a few reports deal with the early changes in the neural retina of diabetic rats. Those include reports of an increase in apoptotic neurons one month after diabetes onset and delayed oscillatory potentials peaks in diabetic rat 2-3 weeks after the onset of diabetes. The conclusion of early retinal neurodegeneration was based on recording electrophysiological changes in the streptozotocin diabetic rats retinas ${ }^{[29,31]}$. The present study coincide with the report of Aizu et al. ${ }^{[29]}$ who reported that the retinal neurons began to degenerate prior to vascular malfunction. In the present work, the cytoplasm of the cells in inner nuclear layer and ganglion cell layer was lucent and showed accumulation of dark stained bodies. Recently, Akeo et al. ${ }^{[32]}$ reported that ferrous ions released from hemoglobin (due to hemorrhage and leakage) and stored transferrin ions cause oxidative stress in the eyes. The changes obtained in the present work were similar to that of the oxidative stress and including the pigment epithelium cells and the photoreceptor cells. Thus, these changes may be due angiopathy followed by edema and/or the toxic effects of the free radicals.

In general, aldose reductase was found in Müller cells of normal rats retinas ${ }^{[11]}$, in Müller cells of normal human retinas ${ }^{[33]}$, in culture pericytes of normal human retinal capillaries ${ }^{[34]}$, and in cultured pericytes of adult rhesus retinal capillaries ${ }^{[12]}$. In the present investigation, Müller cells were affected by sorbitol injection and showed pyknosis. The finding of pyknotic Müller's cells near the inner limiting membrane of sorbitol injected rats retinas may be another causative factor of sorbitol retinopathy which resembles the diabetic retinopathy.

It is well known that Müller cells are the principal glial cells of the neural retina. Müller cells span the entire thickness of the retina and contact all retinal neurons. Müller cells play a role in supporting neuronal survival and information processing. Thus, Müller cells are responsible for the structural stabilization of the retina, because the layered arrangement of the retinal neurons is created and maintained by the Müller cell framework. Müller cells regulate the extra-cellular homeostasis of ions, $\mathrm{pH}$ and water content. Müller cells provide trophic substances to neurons and remove metabolic wastes. Müller cells contribute directly and indirectly to the neuronal information process within the retina, particularly by fast uptake of released neurotransmitters and providing precursors of neurotransmitters to the neurons. Moreover, Müller cells act as intraretinal modulators of immune and inflammatory responses. Müller cells synthesize factors that induce the formation of tight junctions and thus confer barrier properties to retinal vessels and photoreceptors outer segments. In addition, Müller cells synthesize or store a number of growth factors. Therefore, the survival of retinal neurons dependes on Müller cells ${ }^{[35]}$.

Accordingly, any change in Müller cells will disrupt the previously mentioned functions of these cells. Thus, damage of the entire retina may occur. This conclusion may in agreement with the Mizutani et al. report ${ }^{[36]}$, which stated that selective Müller cell functional abnormalities in early stage of the development of diabetic retinopathy, and with the report of Dubois et al. ${ }^{[37]}$, who found Müller cells death causes retinal dysplasia, photoreceptor apopotosis, and finally retinal degeneration and proliferation of the retinal pigment epithelium. Another reason that reinforce the concept of retinal degeneration by sorbitol pathway is the protection or delaying of diabetic retinopathy by using aldose reductase inhibitor (tolrestat) in diabetic rats ${ }^{[14]}$, prevention of glomerular disease by aldose reductase inhibitor (sorbinil) in diabetic rats ${ }^{[38]}$, correcting corneal endothelial changes in diabetic patient by topical aldose reductase inhibitor (placebo) in diabetic patients ${ }^{[39]}$, Prevention of diabetic complications and nerve tissue by aldose reductase inhibitors (sorbinil or sulindac) in rats lens ${ }^{[40]}$, prevention of diabetic retinopathy by aldose reductase inhibitor (sorbinil) in diabetic patients ${ }^{[41]}$, and prevention of basement membrane thickening by aldose reductase inhibitor (sorbinil) in retina of galactosemic rats $^{[3]}$.

According to the previous changes that were concomitant to sorbitol injection, sorbitol is accused in diabetic retinopathy. Moreover, sorbitol is not the only causative factor of diabetic retinopathy. To the author's knowledge, the present work preceded other authors in testing sorbitol toxicity in normal rat retinas. The results obtained in this study are of benefit because it may be a key for a better understanding of diabetic retinopathy. In addition, the study revealed the one of the target tissues of sorbitol toxicity which is the retina.

So it may concluded that sorbitol exerts its effects intracellular and not on the connective tissues. The previous speculation was confirmed by the appearance of cytoplasmic changes of different retinal neuronal cells and pigment epithelium.

The previous assumption be supported by the hypothesis of King et al ${ }^{[42]}$, who reported that sorbitol is accumulated in the vascular and neuronal tissues in the retina of diabetic subjects. In addition, the degradation of sorbitol progresses relatively slowly, resulting in the accumulation of sorbitol inside cells. 
Because sorbitol dose not diffuse across cell membranes easily, it may accumulate and damage the cell as a result of osmotic changes.

In Conclusion, The present investigation concluded that sorbitol played a role in the production of diabetic retinopathy but other toxic pathways may be enhanced its effect. Sorbitol injection $(10 \mathrm{mg} / \mathrm{kg}$ of body weight $)$ in albino rats was toxic to the retinal tissues and caused diabetic like retinal lesions. Lesions were confined to the retinal capillaries, retinal pigment epithelium, neural retina and glial cells

\section{ACKNOWLEDGEMENTS}

I am grateful to Prof. W. Hamza (Biology Dept. Head) for making virtually all biology facilities available for our use. This study was approved by the UAEU Animal Ethics

\section{REFERENCES}

1. Valero, S. 2001. Diabetic retinopathy. eMedicine J., 2:414-424.

2. Ishibashi, T., Tanaka, K., and Taniguchi, Y. 1980. Disruption of blood-retinal barrier in experimental diabetic rats: An elrctron microscopic study. Exp. Eye Res., 30:401-410.

3. Robison, G., Kador, P., and J., K. 1983. Retinal capillaries: Basement membrane thickening by galactosemia prevented with aldose reductase inhibitor. Science, 221:1177-1179.

4. Anderson, H., Stitt, A., Gardiner, T., and Archer, D. 1995. Diabetic retinopathy: Morphometric analysis of basement membrane thickening of capillaries in different retinal layers within arterial and venous environments. Brit. J. of Ophthal. 79:120-1123.

5. Root, H.M., S. and Ditzel, J. 1959. Proliferative retinopathy in diabetes mellitus. J. A. M. A. 169:903-909.

6. Yanoff, M. 1966. Diabetic retinopathy. N. Engl. J. Med., 274:1344-1349.

7. Patz, A. 1980. Studies on retinal neovascularization. Invest. Ophthal. Vis. Sci., 19:1133-1138.

8. Frederick, L. 1993. Diabetic retinopathy. Diabetes care, 16:322-325.

9. Jedziniak, J., Chylack, L., Cheng, H., Gillisk, K., Kalustian, A., and Tung, W. 1981. The sorbitol pathway in the human lens: Aldose reductase and polyol dehydrogenase. Invest. Ophthal. Vis. Sci., 20:314-325.

10. Brownnlee, M. 1992. Glycation products and the pathogenesis of diabetic complications. Diabetes Care, 15:1835-1843.
11. Ludvigson, M., and Sorenson, R. 1980. Immunohistochemical localization of aldose reductase: Rat eye and Kidney. Diabetes, 29:450459.

12. Buzney, S., Frank, R., Varma, S., anishima, T., and Gabby, K. 1977. Aldose reductase in retinal mural cells. Invest. Ophthal. Vis. Sci., 16:392-396.

13. Engerman, R., and Kern, T. 1993. Aldose reductase inhibition fails to prevent retinopathy in diabetic and galactosemic dogs. Diabetes Care, 42: 820825.

14. Robison, G., Nagata, M., Laver, N., Hohman, T., and J., K. 1989. Diabetic- like retinopathy in rats prevented with an aldose reductase inhibitor. Invest. Ophthal. Vis. Sci., 30:2285-2292.

15. Robison, J., Tillis, T., Laver, N., and Kinoshita, J. 1990. Diabetic-related histopathologies of the rat retina prevented with an aldose reductase inhibitor. Exp. Eye. Res., 50: 355-366.

16. Weiye, L., Shuyu, S., Mahin, K., and John, H. 1984. Stimulation of retinal capillary pericyte protein and collagen synthesis in culture by highglucose concentration. Diabetes, 33: 785-789.

17. Hammes, H., Strodter, D., Weiss, A., Bretzel, R., Federlin, k., and Brownlee, M. 1995. Secondary intervention with aminoguanidine retards the progression of diabetic retinopathy in the rat model. Diabetologia, 38:656-660.

18. Glauret, A. 1965. The fixation and embedding of biological specimen. In: Techniques for electron microscopy. D.H. Key, ed. Davis Co., Philadelphia, PP. 166-212.

19. Eva, M. 1993. Diabetic retinopathy. Br. Med. J., 307:1195- 1199.

20. Thomas, J.,1990. Diabetic retinopathy. Exp. Eye Res., 48:55-60.

21. Roberto, Z., and Barry, M. 1986. Pathogenesis of diabetic microangiopathy: The hemodynamic view. Am. J. Med., 80: 443-453.

22. Myron, Y. 1969. Ocular pathology of diabetes mellitus. Am. J. Ophthal., 67:21-37.

23. Klein, R., Klein, B., Moss, S., Davis, M., and DeMetes, D. 1984. The Wisconsin epidemiologic study of diabetic retinopathy. Ophthalmology, 91: 1464-1474.

24. Olka, R. 1986. Modified Grid Argon (Blue-Green) Laser photocoagulation for diffuse diabetic macular edema. Ophthalmolgy., 93 :938-950.

25. Fonseca, V., Munshi, M., Merin, L., and J., B. 1996. Diabetic retinopathy: A review for the primary care physician. South. Med. J. 89: Issue 9. 
26. Yang, C., Cheng, C., Lee, F., Hsu, W., and Liu, J. 2001. Quantitative assessment of retinal thickness in diabetic patients with and without clinically significant macular edema using optical coherence tomography. Acta Ophthal. Scand., 79:266-270.

27. Grimes, P., and Laties, A. 1980. Early morphological alteration of the pigment epithelium in streptozotocin induced diabetes: Increased surface area of the basal cell membrane. Exp. Eye. Res., 30:631-639.

28. Marmorstein, A. 2001. The polarity of the retinal pigment epithelium. Traffic, 2:867-872.

29. Aizu, Y., Oyanagi, K., JHu, J., and Nakagawa, H. 2002. Degeneration of retinal neuronal processes and pigment epithelium in the early stage of the streptozotocin-diabetic rats. Neuropathology 22:161-170.

30. Grahn, B., and Cullen, C. 2001. Retinopathy of great Pyrenees dogs. Fluorescein angiography, light microscopy and transmitting and scanning electron microscopy. Vet. Ophthal., 4:191-199.

31.Lieth, E., Gardner, T., Barber, A., and Antonetti, D. 2000 Retinal neurodegeneration: early pathology in diabetes. Clin. and Exp. Ophthal., 28: 3-8.

32. Akeo, K., Hiramitsu, T., Yorifuji, H., and Okisaka, S. 2002. Membranes of retinal pigment epithelial cells In Vitro are damaged in the phagocytotic process of the photoreceptor outer segment discs peroxidized by ferrous ions. Pigment . Cell Res., 15:341-347.

33. Akagi, Y., Yajima, Y., Kador, P., Kuwabara, T., and Kinoshita, J. 1984. Localization of aldose reductase in the human eye. Diabetes Care, 33:562566.

34. Thomas, C., Chihiro, N., and Gerald, R. 1989. Aldose reductase and polyol in cultured pericytes of human retinal capillaries. Exp. Eye Res., 48:5560.
35. Bringmann, A., and Reichenbach, A. 2001. Role of Müller Cells in retinal degenerations. . Frontiers in Bioscience, 6:77-92.

36. Mizutani, M., Gerhardinger, C., and Lorenzi, M. 1998. Müller cell changes in human diabetic retinopathy.Diabetes, 47:445-449.

37. Dubois-Dauphin, M., Poitry-Yamate, C., de Bilbao, F., Julliard, A., Jourdan, F., and Donati, G. 2000. Early postnatal Müller cell death leads to retinal but not optic nerve degeneration in transgenic mice. Neuroscience, 95:9-21.

38. Beyer-Mears, A., Ku, L., and Cohen, M. 1984. Glomerular poluol accumulation in diabetes and its prevention by oral sorbinil. Diabetes Care, 33: 604607.

39. Ohguro, N.M., M. ; Ohashi ; Y. and Fukuda, M. 1995. Topical aldose reductase inhibitor for correcting corneal endothelial changes in diabetic patients. Brit. J. Ophthal., 79:1074-1077.

40. Jacobson, M., Sharma, Y., Coltlier, E., and Hollander J. 1983. Diabetic complications in lens and nerve and their prevention by sulindac or sorbinil: Two novel aldose reductase inhibitors. Invest. Ophthal. Vis. Sci., 24:1426-1429.

41. Sorbinil Retinopathy Trial Research Group. 1990. A randomized trial of sorbinil, an aldose reductase inhibitor, in diabetic retinopathy. Arch. Ophthal., 108: 1234-1244.

42. King, G., Shiba, T., Oliver, J., Inoguchi, T., and Bursell, S. 1994. Cellular and molecular abnormalities in the vascular endothelium of diabetes mellitus. Annu. Rev. Med., 45: 179- 188. 